\title{
THE ANALYSIS RELATED VARIATION SLICE THICKNESS TO IMAGE INFORMATION RECONSTRUCTION MAXIMUM INTENSITY PROJECTION (MIP) MSCT ABDOMINAL ANGIOGRAPHY IN THE HOSPITAL TELOGOREJO SEMARANG
}

\author{
Yeti Kartikasari $^{\mathrm{i}^{*}}$; Nurdopo Baskoro ${ }^{\mathrm{b}}$; Muhammad Erfansyah'; Anik Setyowati ${ }^{\mathrm{d}}$ \\ a,b,c Poltekkes Kemenkes Semarang; Tirto Agung Pedalangan ; Semarang 50268 ; \\ Indonesia \\ ${ }^{d}$ Bhayangkara Hospital; Majapahit 140 ; Gayamsari ; Semarang 50248 ; Indonesia
}

\begin{abstract}
The Research of this study was to determine the relationship of slice thickness to Maximum Intensity Projection (MIP) reconstructive image information and determine the exact slice thickness to the MIP processing of MSCT examination of Abdominal Angiography. Type of research is quantitative with an experimental approach, using a sample of 6 patients. Each patient performed a MIP reconstruction of the abdominal artery that is truncus coeliacs artery, gastric artery, hepatic artery, splenic artery, superior mesenteric artery, inferior mesenteric artery, renal artery, and communis iliac artery with variations in slice thickness of 5, 10, 15, 20 and $25 \mathrm{~mm}$. Correlation test results produce a P-value $=0.001$ smaller than $\alpha=0.05$ so that Ho is rejected and Ha is accepted, which means there is a relationship between slice thickness with image information on the MIP processing of abdominal arteries. Correlation coefficient value obtained is 0.593 so that the relationship obtained is moderate. The negative relationship is that the smaller the slice thickness, the diagnostic information on the abdominal artery is clearer, the greater the slice thickness, the diagnostic information generated is increasingly unclear. MIP reconstruction of the abdominal artery can produce clear image information on $5 \mathrm{~mm}$ and $10 \mathrm{~mm}$.
\end{abstract}

Keywords: maximum intensity projection (MIP) ; artery abdominal ; slice thickness ; msct abdominal angiography

\section{Introduction}

The abdomen is an organ of the largest of its kind in the body, an oblong form and extends it from above the diaphragm until the pelvis the lowest level of government. Consisting of some to supply liver, the kidneys, of the spleen, pancreas, the stomach, the intestines that they are located which was above the cavity of the pelvis (Pearce, 2011). One of vascularity the abdomen is is the aorta, the abdominal aorta and is a successor to the aorta thoracic processes of now at the end of may reach less than a per cent a ligament arcuate medianus the diaphragm. The aorta abdominal begins with a willing hiatus aortic the diaphragm, as high as vertebra thoracal 12 . Then keep up the

\footnotetext{
*) Corresponding Author (Yeti Kartikasari)

E-mail: yeti.kartikasari@gmail.com
}

go down to retroperitoneum eventually they form two a branch of the aorta bifurcate so that it to the arteries internal iliac that supplies the part the pelvis and the iliac artery external power to supply extremities bottom (Gibson, 2008). A system of vascularity can be visualization with was done if the meeting MSCT Angiography.

Multislice Computed Tomography (MSCT) is one of a means of supporting diagnose that uses a combination of $x$-rays and computed. The results of investigation MSCT able to represent the picture anatomical the human body in the form of a wedge or slice shots discount for the diagnosis of a disease that allows the doctors do in a more accurate. Some action doing, of the patients and his family can see an organ of a certain body without doing it (Rasad, 2006). One of vascularity that could be done by MSCT 
angiography examination on the abdomen.

MSCT Angiography is examination radiology invasive by including a contrast medium through the blood vessels, in order to see veins at the body by the use of MSCT modalities scan. MSCT Angiography has successfully used to detect abnormality and anatomy blood vessels, problems and certain diseases. MSCT angiography useful described the nervous system, the aorta the thorax and aorta abdomen. MSCT angiography abdominal diagnoses abnormalities in the region the abdominal aorta and organs visceral to vascular anatomy. The keys are abnormalities aortic syndrome, abdominal aneurysm, renal artery stenosis of, mesenteric ischemia and tumour (Corey dan Javier, 2007).

According to (Bongartz, 2004; Seeram, 2009) reconstruction images that can be done to the examination of MSCT angiographic covering Multi Planar Reconstruction (MPR), Maximum Intensity Projection (MIP), Volume Rendering Technique (VRT), Curve Planar Reconstruction (CPR), Shaded Surface Display (SSD) dan Fly Through.

To the examination of MSCT angiographic abdominal one of reconstruction, an image that is often done is maximum intensity projection (MIP). MIP is a process of reconstruction to seek a snapshot of the abdominal namely the aorta abdominal artery, the celiac artery, the superior mesenteric artery, an artery hepatica, an artery iliac and arteries with renal slice thickness (Holalkere, 2011). The picture which is a can on MIP that is a picture of an artery abdominal in elongated, will but not necessarily can intact. A picture of MIP more used to distinguish the density of gradations between calcified to a contrast of that is in blood vessels (European Guidelines for Multislice Computed Tomography, 2004).

In processing maximum intensity projection (MIP) there need to be proper thickness election slice shots to get a good abdominal artery. Reconstruction MIP is table to display vascularity on the veins of the abdominal artery well. So that proper thickness with the selection slice shots so to be acquired the image of an artery abdominal with the qualities of an image that is optimal that would give proper diagnostic information. The selection of the size of the slice thickness affects the management MIP (Rober, 2015).

According to (Pelberg, 2015) in processing MIP slice thickness used too small so a detail that produced were not clear, and if slice shots thickness used too large and can show stenosis of small but a disorder that does not look, and difficult to see whack in detail. So that the selection of the right slice thickness has been quite influential in providing information on diagnosing which needed.

Examination MSCT angiography Abdominal at the hospital Telogorejo Semarang done for detecting the presence of abdominal an abnormality of the arteries. Rekonstrusi processing MIP done at the hospital Telogorejo Semarang use slice thickness is $5 \mathrm{~mm}$. In processing MIP reconstruction there are no guidebooks which the exact slice thickness used to get an optimal abdominal artery.

Slice thickness a bad can affect information diagnose produced, so as to cause a specialist radiology difficulty in giving diagnose. Therefore it needed further analysis of how to slice thickness most qualified to get an artery abdominal optimal MIP on processing.

\section{Method}

The kind of research is quantitatively used by approach experimental. The data place in installation radiology hospital Telogorejo Semarang. Subjects research is diagnostic information obtained from MIP processing with slice thickness $5 \mathrm{~mm}, 10 \mathrm{~mm}, 15 \mathrm{~mm}, 20 \mathrm{~mm}$ and $25 \mathrm{~mm}$ with respondents 3 doctor radiology have 5 years old and upward competent giving an assessment to examination MSCT angiography abdominal.

The population used patients were MSCT angiography abdominal with 6 sample patients. Patients in plain MSCT Abdomen first with slice thickness $5 \mathrm{~mm}$. Then a contrast medium injection automatically connected with an intravenous feeder cubitus through a vein, the as follows:
1) Flow Rate $: 3,5 \mathrm{ml} / \mathrm{s}$
2) Iodium Concentration $: 370 \mathrm{mg} . \mathrm{I} / \mathrm{ml}$
3) Media Contrast Volume : $80 \mathrm{ml}$
4) saline : Nacl 20ml

After injection of the contrast medium, the patient is scanned from the xypoideus processus to the pubic symphysis with a $5 \mathrm{~mm}$ slice thickness. Scanning results in recon with thinness thin slice of $0.625 \mathrm{~mm}$. Then the reconstructed image results sent to 3D and reformed with $5 \mathrm{~mm}$, $10 \mathrm{~mm}, 15 \mathrm{~mm}, 20 \mathrm{~mm}$, and $25 \mathrm{~mm}$ slice thickness. The next step is to reconstruct MIP images so as to get a picture of blood vessels that will be assessed by the radiologist. By setting the window width at $1000 \mathrm{HU}$, and the window level 
at $550 \mathrm{HU}$. MIP processing results are printed using a radiograph film. Then radiograph results are submitted to the radiologist to be assessed by providing a checklist assessment image information.

The six MIP reconstruction results with 5 variations of each patient's slice thickness were assessed by the radiologist to obtain an image information value in the abdominal artery. Results of MIP overview examination of MSCT Abdominal Angiography with the variation of slice thickness using an instrument in the form of a questionnaire sheet. The questionnaire contains a table with eight assessed anatomical criteria, the table being a description of the truncus celiacus artery, the gastric artery, the hepatic artery, the lienal artery, the superior mesenteric artery, the inferior mesenteric artery, the renal artery, and the communic iliac artery resulting from anatomical artery abdominal looks clear, arterial walls bordered firmly and visibly smooth, not visible blur and easily seen by the observer.

The range of values is 1 to 3 , the value 1 is the minimum value and the value 3 is the maximum value. So each artery will have a score of 18 as the highest value and 6 as the lowest value.

\section{Result and Discussion}

The data of the questionnaire are shown in the following table:

a. Assessment of MIP on Slice Thickness $5 \mathrm{~mm}$

Based on Figure 1. MIP in $5 \mathrm{~mm}$ slice thickness, celiacus truncus artery, hepatic artery, lienalis artery, superior mesenteric artery and inferior mesenteric artery, gastric artery, renal artery and communic iliac artery are evident.

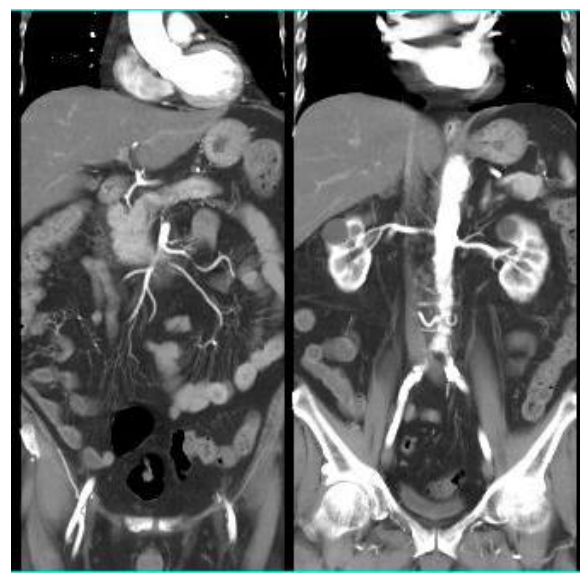

Figure 1. MIP Reconstruction Results (5 mm Slice Thickness) b. Assesment of MIP on Slice Thickness $10 \mathrm{~mm}$

Based on Figure 2. MIP on a $10 \mathrm{~mm}$ slice thickness, the cuncture trelius artery and the gastric artery appear quite clear. The hepatic artery of the lienal artery, the superior mesenteric artery, the inferior mesenteric artery, the renal artery and the communic iliac artery are apparent.

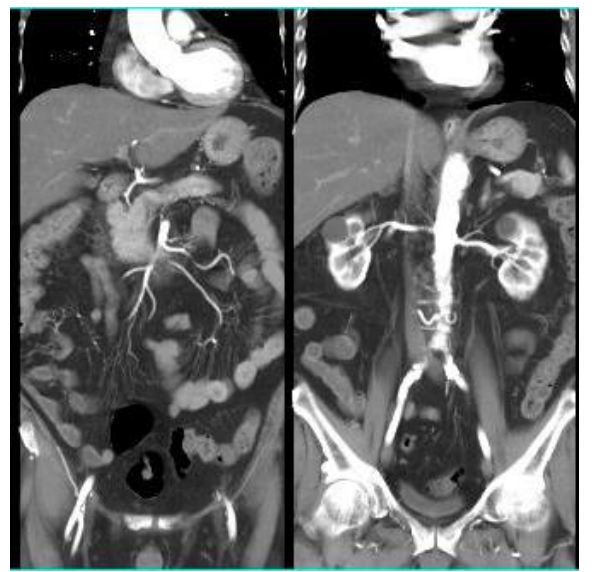

Figure 2. MIP Reconstruction Results (10 mm Slice Thickness)

c. Assessment of MIP on $15 \mathrm{~mm}$ Slice Thickness

Based on Figure 3. MIP on $15 \mathrm{~mm}$ thickness, cuncture trelius artery, superior mesenteric artery, hepatic artery, renal artery and gastric artery appear less clear. The lienali artery, the inferior mesenteric artery and the communic iliac artery are evident.

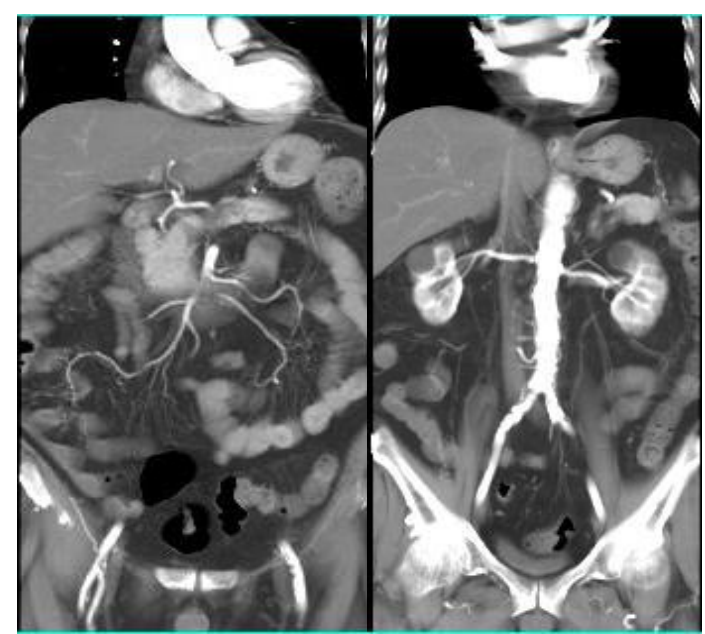

Figure 3. MIP Reconstruction Results (15 mm Slice Thickness)

d. Assessment of MIP on $20 \mathrm{~mm}$ Slice Thickness

Based on Figure $4.4 \mathrm{MIP}$ on $20 \mathrm{~mm}$ Slice Thickness, celiacus truncus artery, superior 
mesenteric artery, inferior mesenteric artery, hepatic artery, lienalis artery, renal artery and communicall iliac artery appear less clear whereas the gastric artery appears unclear.

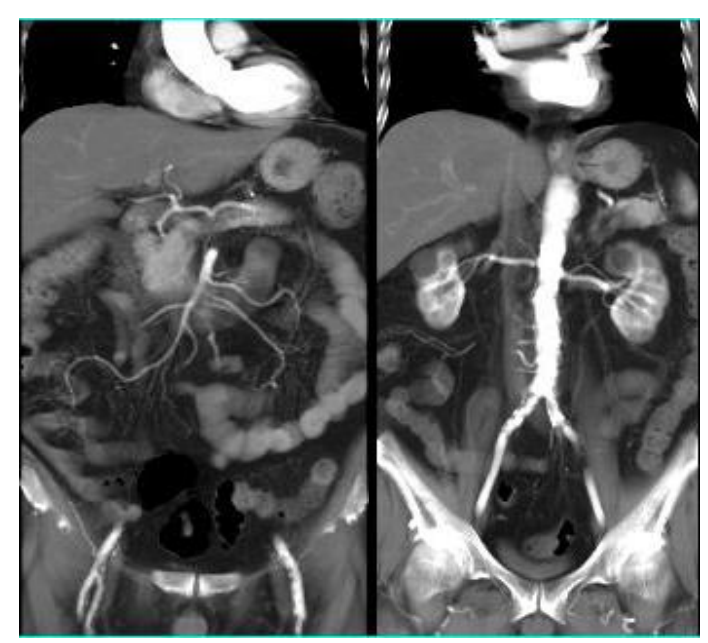

Figure 4. MIP Reconstruction Results (20 mm Slice Thickness)

e. Assessment of MIP on $25 \mathrm{~mm}$ Slice Thickness

Based on Figure 5. MIP on $25 \mathrm{~mm}$ slice thickness, celiacus truncus artery, hepatic artery, lienalis artery, superior mesenteric, inferior mesenteric artery, renal artery and communicall iliac artery appear less clear whereas gastric artery is unclear.

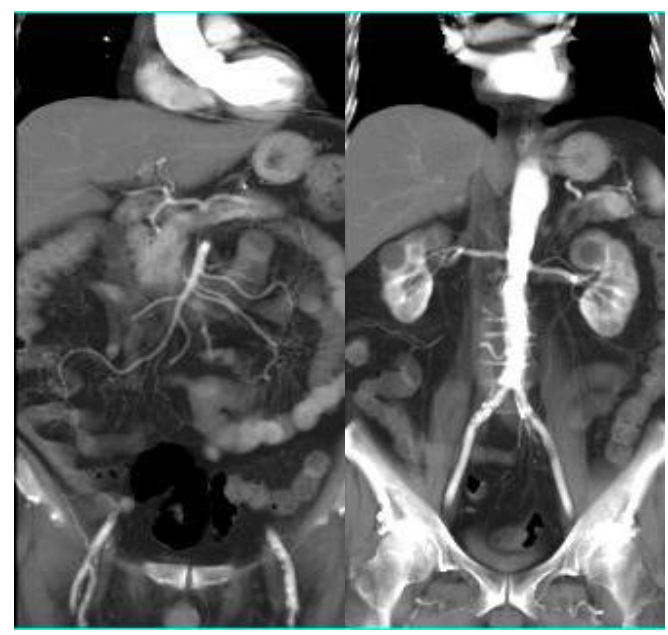

Figure 5. MIP Reconstruction Results (25 mm Slice Thickness)

Based on Figure 1. shows the value of celiacus truncus artery score, gastric artery, hepatic artery, lienal artery, superior mesenteric artery, inferior mesenteric artery, renal artery, and communicular iliac artery at $5 \mathrm{~mm}$ and 10 $\mathrm{mm}$ slice thickness have high mean score ie at 17.37 and 16.75 , at $15 \mathrm{~mm}$ slice thickness of 16.75 , at $20 \mathrm{~mm}$ slice thickness of 11.87 and $25 \mathrm{~mm}$ slice thickness of 11.37 .

From the data, it can be concluded that the slice thickness value given high value by the respondent is $5 \mathrm{~mm}$ and $10 \mathrm{~mm}$ slice thickness. Respondents argue that the result of MIP images of the abdominal aorta using $5 \mathrm{~mm}$ and $10 \mathrm{~mm}$ slice thickness is the resulting radiograph with the boundary between the vascular and the tissue very clearly and firmly. The results of the analysis of this recapitulation do not differ from the results of the analysis with statistical tests, the results are as follows.

Slice thickness relationship in the processing of Maximum Intensity Projection (MIP) of abdominal artery against diagnostic information on MSCT Abdominal Angiography examination.

After all, data has been collected, a statistical test is performed to determine the correlation of slice thickness in the processing of Maximum Intensity Projection (MIP) of an abdominal artery to diagnostic information on MSCT Abdominal Angiography examination. Statistical data processing using SPSS version 16 program with correlation test to determine the relationship of slice thickness with image information.

Table 1. Recapitulation of MIP Assessment on Slice Thickness Variations $5 \mathrm{~mm}, 10 \mathrm{~mm}, 15 \mathrm{~mm}$, $20 \mathrm{~mm}$ and $25 \mathrm{~mm}$.

\begin{tabular}{lccccc}
\hline \multicolumn{1}{c}{ Anatomy } & $\begin{array}{c}5 \\
\mathrm{~mm}\end{array}$ & $\begin{array}{c}10 \\
\mathrm{~mm}\end{array}$ & $\begin{array}{c}15 \\
\mathrm{~mm}\end{array}$ & $\begin{array}{c}20 \\
\mathrm{~mm}\end{array}$ & $\begin{array}{c}25 \\
\mathrm{~mm}\end{array}$ \\
\hline $\begin{array}{l}\text { Truncus Coeliacus } \\
\text { Artery }\end{array}$ & 18 & 16 & 14 & 12 & 11 \\
Gastric Artery & 16 & 14 & 10 & 9 & 9 \\
Liver Artery & 18 & 18 & 14 & 11 & 11 \\
Lienalis Artery & 18 & 8 & 15 & 11 & 11 \\
$\begin{array}{l}\text { Mesenteric Superior } \\
\text { Artery }\end{array}$ & 18 & 17 & 16 & 12 & 12 \\
$\begin{array}{l}\text { Mesenteric Inferior } \\
\text { Artery }\end{array}$ & 18 & 17 & 13 & 12 & 12 \\
$\begin{array}{l}\text { Renalis Artery } \\
\text { Iliaca Comunis }\end{array}$ & 16 & 17 & 16 & 14 & 12 \\
$\begin{array}{l}\text { Artery } \\
\text { Number of }\end{array}$ & 139 & 134 & 114 & 95 & 91 \\
$\begin{array}{l}\text { Scores/Slice } \\
\text { Score Value/ Slice }\end{array}$ & 17.37 & 16.75 & 14.25 & 11.87 & 11.37 \\
Thickness & & & & & 14 \\
\hline
\end{tabular}


Data obtained respondents then tested the normality of data. Based on the Spearman correlation test results with SPSS program obtained the following results:

Table 2. Results Spearman Correlation Between Slice Thickness with Image Information

\begin{tabular}{ccccc}
\hline Description & & Results & & Mean \\
\cline { 1 - 1 } \cline { 5 - 5 } p-value & & 0.001 & & There is a Correlation \\
$\mathrm{r}$ & & -0.593 & & Medium Correlation \\
\hline
\end{tabular}

Based on the above table it can be seen that the value of $P$-value produced is 0.001 smaller than $\alpha=0.05$, so it can mean a significant or significant relationship between slice thickness with diagnostic information. With a significant relationship then Ho is rejected and Ha accepted.

Based on the output of SPSS result of spearman correlation can be explained that there is a correlation of slice thickness in the processing of Maximum Intensity Projection (MIP) of an abdominal artery to image information on examination of MSCT Abdominal Angiography. From the statistical data obtained the value of correlation (0.593), then the value of correlation coefficient between 0.400-0.599 which means that the correlation between slice thickness with medium image information. Negative correlation coefficient value means that the slice thickness relationship with the diagnostic information is the opposite. This may mean thinner slice thickness, the more obvious the diagnostic information, and the thicker the slice thickness the more obvious the diagnostic information becomes.

Based on the results of statistical tests with the Spearman Correlation test obtained p-value value is 0.001 . This means that the value of $P$-value is 0.001 smaller than $\alpha=0.05$, thus there is a relationship between slice thickness with image information significantly. So that can be interpreted Ho rejected and Ha accepted. In other words, it can be concluded that there is a correlation of slice thickness in the processing of Maximum Intensity Projection (MIP) of the abdominal artery to image information on MSCT Abdominal Angiography examination. According to the author, this is in accordance with the theory of Budoff (2010), which says Maximum Intensity Projection (MIP) is a three-dimensional reconstruction used to see the body's tissues to the maximum intensity. MIP images present a series of images in the form of slabs as a single image. The number of images included in the slab can be adjusted and determined by the thickness of the slab.

Based on research data with the statistical test can be known coefficient correlation value (0.593) which means that the relationship between slice thickness with image information produced medium correlated because of the value of correlation coefficient between 0.400 0.599 and negative value which can be interpreted the relationship between slice thickness with diagnostic information opposite direction. This means that the smaller the slice thickness will be the clearer the image information, on the contrary increasingly slice thickness the more unclear the resulting image information.

Selection of appropriate slice thickness in abdominal artery MIP processing in MSCT Abdominal Angiography examination.

After MIP processing of abdominal artery at $5 \mathrm{~mm}, 10 \mathrm{~mm}, 15 \mathrm{~mm}, 20 \mathrm{~mm}$, and $25 \mathrm{~mm}$ slice thickness and based on data obtained from the respondents, the diagnostic information of the abdominal artery is seen clearly in the treatment with $5 \mathrm{~mm}$ and $10 \mathrm{~mm}$ slice thickness. Based on respondent data on $5 \mathrm{~mm}$ thickness and $10 \mathrm{~mm}$ abdominal artery diagnostic information obtained a high score. So that MIP processing of the abdominal artery will get information about the abdominal image of an artery which bounded firmly and clearly on slice thickness 5 $\mathrm{mm}$ and $10 \mathrm{~mm}$.

Due to time constraints, in this study the author uses a variation of slice thickness of $5 \mathrm{~mm}$, so the author did not do research with slice thickness below $5 \mathrm{~mm}$. This study was conducted with the smallest $5 \mathrm{~mm}$ slice thickness with a scale of 5 for the variation. It is intended that the resulting image information difference is not too confusing the respondent in giving an assessment of clarity of coronary artery resulting from MIP processing and variation with scale 5 resulted in a significant difference to the image information.

Based on the results of the assessment of the three respondents obtained the assessment of clarity of abdominal artery image information with variations of slice thickness on the MIP processing of MSCT Abdominal Angiography examination. In the $5 \mathrm{~mm}$ slice thickness variation obtained scores of information assessment of the abdominal artery image that clearly showed scores of 17.37. At $10 \mathrm{~mm}$ slice 
thickness variation obtained score assessment of abdominal arterial image information that clearly showed scores of 16.75 . In the slice thickness variation of $15 \mathrm{~mm}$, obtained score assessment information abdominal arterial image that still looks clear has a score of 14.25. In the variation of slice thickness $20 \mathrm{~mm}$, obtained score assessment information abdominal artery image that looks quite clear and does not clearly have a value of 11.87. In the slice thickness variation of $25 \mathrm{~mm}$, obtained score assessment of abdominal arterial image information that seems unclear has a score of 11.37.

Based on the evaluation of image information on MIP processing, the information obtained on the abdominal artery image is clear in the MIP treatment with $5 \mathrm{~mm}$ and $10 \mathrm{~mm}$ slice thickness with score 17.37 and 16.75. MIP processing on slice thickness $15 \mathrm{~mm}$ obtained score value 14.25 image information is still visible. MIP processing at slice thickness $20 \mathrm{~mm}$ obtained score value 11.87 image information seen quite clear and not clear. While the assessments obtained in the assessment of unclear after abdominal image information obtained on MIP treatment with $25 \mathrm{~mm}$ slice thickness is 11.37.

According to (Budoff, 2010), Maximum Intensity Projection (MIP) is a three-dimensional reconstruction used to view body tissues to the maximum intensity. MIP images present a series of images in the form of slabs as a single image. The number of images included in the slab can be adjusted and determined by the thickness of the slab. According (Pelberg Robert, 2015) it is said that if in MIP processing the slice thickness used is too small then the resulting detail is less clear, whereas if the slice thickness used is too large it can show stenosis but small abnormalities are not visible, and it is difficult to see plaque details.

According to the author's analysis, this is in accordance with the theory that to obtain a picture of the abdominal image of the arterial image that is firm and clear on the examination of MSCT Abdominal Angiography required the processing of MIP with appropriate slice thickness. This is evidenced in the assessment of respondents. In MIP treatment with $5 \mathrm{~mm}$ slew thickness and $10 \mathrm{~mm}$ of respondents stated that abdominal artery diagnostic information is apparent. While in MIP treatment with $25 \mathrm{~mm}$ slice thickness of respondents most of the time stated that abdominal artery diagnostic information seems unclear or blurred.
According to Bongartz (2004) that MIP reconstruction is used to view the image of the abdominal artery by adjusting the thickness of the image. Based on the data obtained this is consistent with the theory that produces a clearly visible abdominal artery in MIP treatment with 5 $\mathrm{mm}$ and $10 \mathrm{~mm}$ slice thickness is Truncus Coeliacus Artery, Gastrika Artery, Hepatic Artery, Lienalis Artery, Superior Mesenteric Artery, Inferior Mesenteric Artery, Renal Arteries, Iliaka Communist Arteries. In MIP treatment with $15 \mathrm{~mm}$ diameter thickness of Truncus Coeliacus Artery, Hepatic Artery, Lienalis Artery, Superior Mesenteric Artery, Inferior Mesenteric Artery, Renal Artery, Iliaka Communist Artery is still visible, while the Gastrika Artery looks quite clear. In MIP treatment with $20 \mathrm{~mm}$ slice thickness Artery Truncus Coeliacus, Superior Mesenteric Artery, Inferior Mesenteric Artery, Renal Artery, Iliaka Communist Artery is still visible and quite clear, whereas in the Gastrika Artery, Hepatic Artery, Lienalis Artery, seen quite clearly and unclear. In MIP treatment with $25 \mathrm{~mm}$ slices thickness of Truncus Coeliacus Artery, Inferior Mesenteric Artery, Renal Artery, Iliaka Communist Artery looks quite clear, while Gastrika Artery, Hepatic Artery, Lienalis Artery, Superior Mesenteric Artery look unclear.

Based on this research and the data obtained, the writer can analyze that MIP processing of abdominal artery to get the right image information obtained at the processing by using slice thickness $5 \mathrm{~mm}$ and $10 \mathrm{~mm}$ because in the use of $5 \mathrm{~mm}$ and $10 \mathrm{~mm}$ slice thickness abdominal wall image information can be visible bordered and clear. If the slice thickness used is too large the small abnormalities will not be visible. So to get the optimal image information then the examination MSCT Abdominal Angiography in Radiology service should be performed by MIP processing of the abdominal artery by using $5 \mathrm{~mm}$ and $10 \mathrm{~mm}$ slice thickness.

\section{Conclusion and Suggestion}

There is a significant relationship between abdominal artery MIP processing by using a variation of slice thickness. In the correlation test, $\mathrm{P}$-value value $=0.001$ smaller than $\alpha=0.05$ so that the hypothesis Ho rejected and Ha accepted means there is a relationship of slice thickness to abdominal artery diagnostic information on MIP processing on the examination of MSCT Abdominal Angiography. The correlation 
coefficient value obtained 0.593 and negative value which means the correlation between slice thickness with medium image and the opposite direction is that the thin slice thickness then the resulting diagnostic information is clear, whereas the thicker the slice thickness the diagnostic information generated more unclear.

From the results of this study can be concluded that the MIP processing of abdominal artery in the examination of MSCT Abdominal Angiography with $5 \mathrm{~mm}$ slice thickness and 10 $\mathrm{mm}$ image information produced is clear while the slice thickness of $15 \mathrm{~mm}$ image information obtained is still apparent. For $20 \mathrm{~mm}$ slice thickness and $25 \mathrm{~mm}$ of abdominal artery MIP processing in the MSCT Abdominal Angiography examination, the picture was unclear. So it can be concluded that the amount of slice thickness that can produce image information in the MIP processing of abdominal arteries that can produce the wall of the abdominal artery is firmly defined in the slice thickness between $5 \mathrm{~mm}$ and $10 \mathrm{~mm}$.

\section{Acknowledgements}

Thanks go to Poltekkes Kemenkes Semarang for providing funding for research activities. Thank you also conveyed to installation radiology hospital Telogorejo Semarang who has given permission to conduct research.

\section{References}

Bongartz G. S.J. Golding, A.G. Jurik, M. Leonardi, et al 2004, European Guidelines for Multislice Computed Tomography. Funded by the European Commission.

Bushberg. J.T. 2003, The Essential Physics Of Medical Imaging, Second Edition. Philadelphia. USA.

Corey Goldman \& Javier Sanz, 2007. CT Angiography of the Abdominal Aorta and Its Branches with Protocol. Informa healthcare. Chennai.

Gibson, John. 2002, Fisiologi dan Anatomi Modern untuk Perawat. EGC: Jakarta.

Holalkere, NS, et al. 2011. 64-Slice Multidetector Row CT Abdomen of the Abdomen. Department of Radiology, Boston, USA.

Pearce, Evelyne C. 2011. Anatomy dan Fisiologi Untuk Paramedis. Gramedia: Jakarta.

Pelberg, Robert. 2015. Cardiac Angiography Manual. Second Edition. Springer New York USA.

Rasad, S, et al. 2006. Radiologi Diagnostik. Balai penerbit FKUI RSCM: Jakarta.

Seeram, Euclid, RT (R), BSc., MSc., FCAMRT., 2009. Computed Tomography Physical Principle, clinical Application, and Quality Control. 3rd Edition. W.B. Saunders Company, London. 